\section{Cellular Mechanisms of Reproductive Barriers in Some Crosses of Water Lily (Nymphaea spp.) Cultivars}

\author{
Chun-Qing Sun, Zhi-Hu Ma, Guo-Sheng Sun, and Zhong-Liang Dai \\ Zhenjiang Agricultural Research Institute, Jurong 212400, Jiangsu, China
}

\author{
Nian-jun Teng \\ College of Horticulture, Nanjing Agricultural University, Nanjing 210095, \\ China
}

\author{
Yue-Ping Pan ${ }^{1}$ \\ Zhenjiang Agricultural Research Institute, Jurong 212400, Jiangsu, China
}

Additional index words. artificial crossing, pollen viability, pistil receptivity, embryo abortion, seed set

\begin{abstract}
Reproductive barriers exist in some water lily crosses that result in low seed set and low breeding efficiency. We investigated pollen morphology, pollen viability, microspore development, pistil receptivity, and embryo and endosperm development in six water lily crosses using paraffin section as well as light and scanning electron microscopy (SEM) techniques. The results indicated that the percentage of pollen with normal morphology ranged from $8.9 \%$ to $55.2 \%$. The pollen viabilities of 'Fen Zhuang', 'Bai Lu', and 'Hong Ying' were 33.9\%, 3.3\%, and 20.7\%, respectively. Stigmatic pollen germination peaked at $12 \mathrm{~h}$ after pollination and varied from 0.3 to 65.7 grains per stigma among the crosses. The production of embryos with normal morphology ranged from $0 \%$ to $43.6 \%$ at 5 days after pollination, from $0 \%$ to $31.4 \%$ at 15 days after pollination, and from $0 \%$ to $19.7 \%$ by 20 days after pollination. The seed sets of the six crosses were from $0 \%$ to $10.9 \%$. Our results suggest that the low seed set in some crosses is the result of low pollen viability, low pistil receptivity, and embryo abortion.
\end{abstract}

Water lilies (Nymphaea spp.) are important ornamental flower plants that are widely cultivated in gardens for the purpose of environment beautification as well as water purification. According to their ecological characteristics, water lilies can be divided into two categories: hardy water lilies and tropical water lilies. Hardy water lilies are divided into five types according to their tubers: marliac, odorata, tuberosa, and finger types as well as underground rhizome (Huang et al., 2009). As the Chinese economy and living standards have rapidly improved, the demand for water lilies with novel traits has increased. Therefore, Chinese breeders have made efforts to develop new cultivars using methods such as artificial interspecific hybridization, mutation techniques, and multiploid approaches. The most widely used method currently is hybridization when developing water lily cultivars. However, the existence of incongruity barriers often makes many water lily crosses difficult, which reduces the breeding efficiency. To date, only a few previous studies have been carried out

Received for publication 22 July 2014. Accepted for publication 4 Nov. 2014.

This work was supported by the Fund of Independent Innovation of Agricultural in Jiang Su Province of China [CX(11)4005].

${ }^{1}$ To whom reprint requests should be addressed; e-mail panyueping1224@163.com. germination, or embryo abortion. Pollen quality, pistil receptivity, and embryo and endosperm development have been widely examined in many crops, for example, Dendranthema grandiflorum, Nelumbo nucifera, Phaseolus vulgaris, and Fragaria ananssa (Marta et al., 2004; Ndoutoumou et al., 2007; Sun et al., 2010; Teng et al., 2012), and many of these studies successfully revealed the causes of the reduced seed production and breeding efficiency. For instance, in a study of the factors that affect seed set in several chrysanthemum crosses, it was found that a low number of germinated pollen grains and the abnormal growth of most pollen tubes were the main causes of the failure of the cross between D. grandiflorum 'Yuhuaxingchen' and D. nankingense (Sun et al., 2010). In the present study, we screened the three cultivars Fen Zhuang, Bai Lu, and Hong Ying and systematically investigated factors that may affect breeding efficiency of water lily. These factors included pollen morphology, pollen viability just before artificial pollination, germination behavior of pollen grains on stigmas, and embryo development after fertilization.

\section{Materials and Methods}

Experimental materials. Three cultivars, Bai Lu, Fen Zhuang, and Hong Ying, were used in this study (Fig. 1; Table 1). They are hardy water lilies with chromosome number of $112(2 \mathrm{n}=8 \mathrm{x}=112)$. The plants were grown in ponds in Xingxiang town, Zhenjiang, China. Reciprocal crosses were made among three cultivars where 'Fen Zhuang' $x$ 'Hong Ying' was denoted as FH and its reciprocal cross was referred to as HF; 'Bai Lu' $\times$ 'Hong Ying' as $\mathrm{BH}$ and its reciprocal cross as HB; and 'Fen Zhuang' $\times$ 'Bai Lu' as $\mathrm{FB}$ and its reciprocal cross as BF.

The cultivars used in this work were selected for two main reasons. First, the ornamental values of 'Fen Zhuang' and 'Bai Lu' are complementary; for example, the flower color of 'Fen Zhuang' is pink, whereas that of 'Bai Lu' is white. If these two cultivars could be crossed successfully, it would be possible to obtain genotypes with novel traits. Second, preliminary studies indicated that seed set differed among the crosses, which motivated us to examine the factors that influence the fecundity of these crosses. Flowers from multiple plants of each cultivar were used in this study, which was because one plant was unable to produce a sufficient number of flowers for the experiment. the genetic distance among the cultivars. It may be related to pollen quality, pollen
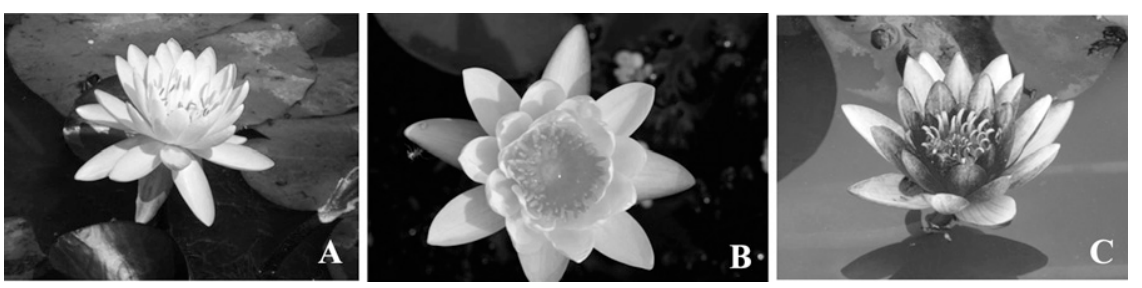

Fig. 1. Morphology of the inflorescence. (A) Nymphaea 'Fen Zhuang'. (B) Nymphaea 'Bai Lu'. (C) Nymphaea 'Hong Ying'. 
Determination of pollen viability. On sunny days, fresh pollen grains were collected from 0900 to $1000 \mathrm{HR}$. The pollen grains were distributed on a glass slide coated with culture medium comprising $300 \mathrm{~g} \cdot \mathrm{L}^{-1}$ sucrose, $10 \mathrm{mg} \cdot \mathrm{L}^{-1} \quad \mathrm{H}_{3} \mathrm{BO}_{3}, 0.8 \mathrm{~g} \cdot \mathrm{L}^{-1} \mathrm{CaCl}_{2} \cdot 2 \mathrm{H}_{2} \mathrm{O}$, $0.9 \mathrm{~g} \cdot \mathrm{L}^{-1} \mathrm{KNO}_{3}$ and $100 \mathrm{~g} \cdot \mathrm{L}^{-1} \mathrm{PEG} 4000$ and then incubated at $20^{\circ} \mathrm{C}$. After $6 \mathrm{~h}$ of culturing, the germination rates of the pollen grains were determined from 10 optical fields (at least 60 pollen grains in each optical field) with an Olympus BX41 microscope (Olympus Co. Ltd., Shanghai, China). Pollen grains were scored as viable when the pollen tube length was longer than the diameter of the pollen grain (Tang et al., 2009). Each experiment was repeated three times and statistical analysis was performed according to Tukey's test.

Artificial pollination. Water lilies are insect-pollinated and their pistil matures 1 or $2 \mathrm{~d}$ before the stamen; thus, we did not emasculate the flowers of the female parent and only bagged them $2 \mathrm{~d}$ before their pistils matured (Huang et al., 2009). The best time for pollination ranges from 0800 to $1000 \mathrm{HR}$ on sunny days (Huang et al., 2009). When the flowers opened and the stigmas were full of bright mucus, the pollen grains of the bagged male flowers were collected for artificial pollination. The stigmas were pollinated with fresh pollen grains from male parents. After artificial pollination, the female flowers were bagged again. The crosses were performed from late September to early Oct. 2013, when the average temperature was $\approx 27{ }^{\circ} \mathrm{C}$ with a range of 26 to $30^{\circ} \mathrm{C}$.

Pollen morphology and behavior on stigmas after pollination. The pollen samples were collected from fresh flowers fixed in $2.5 \%$ glutaraldehyde $(0.1 \mathrm{M}$ phosphate buffer, $\mathrm{pH}=7.2)$ and stored at $4{ }^{\circ} \mathrm{C}$ until use. The detailed surface ornamentation and aperture characteristics were examined under a SEM and photomicrographs were taken.

Minor modifications to the method of Sun et al. (2010) were made and it was used to monitor the in vivo pollen germination on the stigmas. Twenty pistils at each time point per cross were fixed in $2.5 \%$ glutaraldehyde (0.1 M phosphate buffer, $\mathrm{pH}=7.2) 2,6,12$, and $24 \mathrm{~h}$ after pollination.

After that, the pollen and pistil samples were dehydrated in an ethanol series $(40 \%$, $70 \%, 90 \%$, and $100 \%, 15$ min each time), subjected to critical point drying, and coated with gold for SEM (Hitachi S-3000N; Hitachi Co. Ltd., Beijing, China) analysis, and images were processed digitally (Jin et al., 2010).

Examination of microspore development, embryo development, endosperm development, and seed set. Floral buds $0,5,10,15,20$, and $25 \mathrm{~d}$ before blossom were fixed in FAA (5:5:90 formalin: acetic acid:70\% ethanol) and stored at room temperature until they were used for the examination of microspore development. Approximately 200 ovaries were collected from 10 flowers on five plants (two flowers per plant) for each parental combination at 2, 5, $8,12,15$, and $20 \mathrm{~d}$ after pollination and stored in FAA at $4{ }^{\circ} \mathrm{C}$ for the examination of embryo and endosperm development. These samples were dehydrated through a graded series of ethanol solutions $(70 \%, 85 \%, 95 \%$, and $100 \%$, $5 \mathrm{~min}$ in each solution), infiltrated with xylene, and embedded in paraffin wax. Sections were cut to a thickness of 8 to $10 \mu \mathrm{m}$ using a Leica RM2016 microtome (Shanghai Leica Instruments Co. Ltd., Shanghai, China), stained in Heidenhain's hematoxylin, and were observed and photographed under a Zeiss Axioskop 40 microscope (Carle Zeiss Management Co. Ltd., Shanghai, China) (Deng et al., 2010a). In addition, 200 ovaries per cross per time point $(2,5,8,12,15$, and $20 \mathrm{~d}$ after pollination) were examined using a stereomicroscope (Nanjing Jiangnan Yongxin Optical Co. Ltd., Nanjing, China) with digital camera, and the percentage of normal embryos was calculated.

One month after artificial pollination, $\approx 30$ water lily seed pods were randomly chosen and plump seeds were collected from them. Then the seed set in each cross was calculated using the following formula: seed set $=$ (number of plump seeds/total number of pollinated ovules) $\times 100 \%$.

Statistical analysis. The data were subjected to a one-way analysis of variance using SPSS 16.0 (SPSS Inc., Chicago, IL). The means were compared using the Bonferroni

Table 1. Materials used in this study.

\begin{tabular}{llll}
\hline Main characters & \multicolumn{1}{c}{ Fen Zhuang } & \multicolumn{1}{c}{ Bai Lu } & \multicolumn{1}{c}{ Hong Ying } \\
\hline Ecological type & Hardy water lilies & Hardy water lilies & Hardy water lilies \\
Tuber type & Odorata tuber & Marliac tuber & Marliac tuber \\
Flower color & Pink & White & Purple red \\
Flower diameter & 14 to $17 \mathrm{~cm}$ & 12 to $14 \mathrm{~cm}$ & 10 to $13 \mathrm{~cm}$ \\
Leaf color & Grass green & Grass green & Grass green \\
Leaf diameter & $25.4 \mathrm{~cm}$ & $22 \mathrm{~cm}$ & $18 \mathrm{~cm}$ \\
Flowering phase & June to October & June to October & June to October \\
\hline
\end{tabular}
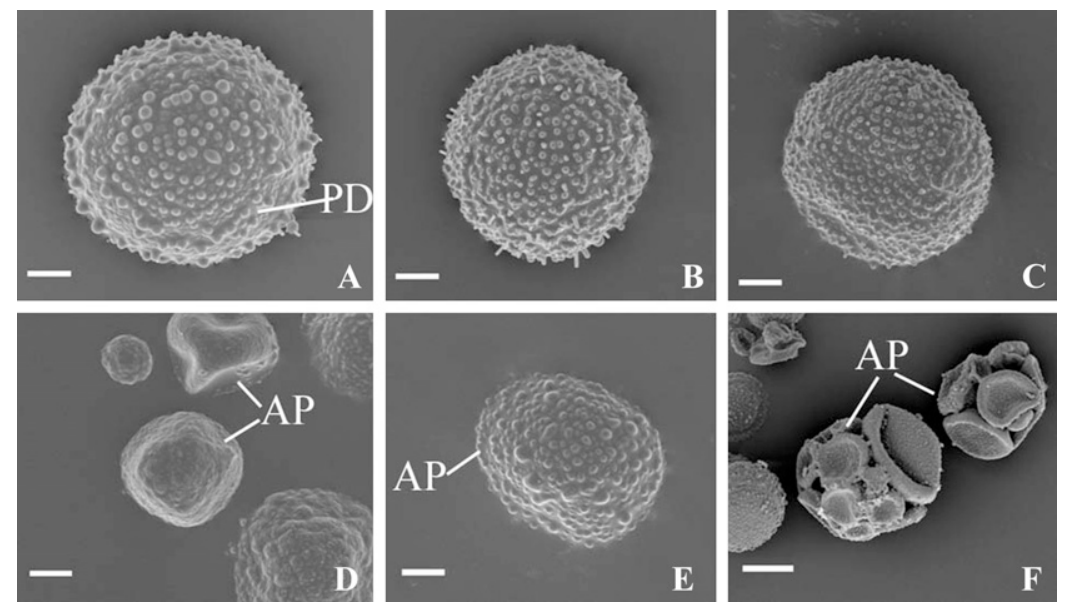

Fig. 2. Scanning electron micrographs of pollen grains in Nymphaea spp. cultivars. (A) Pollen morphology of 'Fen Zhuang'. (B) Pollen morphology of 'Hong Ying'. (C) Pollen morphology of 'Bai Lu'. (D-F) Abnormal pollen of 'Bai Lu'. $\mathrm{PD}=$ pollen ditch; $\mathrm{AP}=$ abnormal pollen; scale bar $=6 \mu \mathrm{m}$.

Table 2. Pollen diameter and percentage of pollen with normal morphology in the three cultivars. ${ }^{\mathrm{z}}$

\begin{tabular}{lcc}
\hline Cultivar & Pollen diam $(\mu \mathrm{m})$ & Normal pollen $(\%)$ \\
\hline Fen Zhuang & $32 \pm 0.4 \mathrm{a}$ & $85.2 \pm 5.1 \mathrm{a}$ \\
Hong Ying & $30.5 \pm 0.9 \mathrm{a}$ & $68.3 \pm 5.5 \mathrm{~b}$ \\
Bai Lu & $20.3 \pm 4.9 \mathrm{~b}$ & $8.9 \pm 0.9 \mathrm{c}$ \\
\hline
\end{tabular}

${ }^{2}$ Values (mean $\pm \mathrm{SD}$ ) followed by the same letter are not significantly different at $\alpha=0.05$ with the Bonferroni $t$ test. The pollen grains were collected from 10 flowers on five plants (two flowers per plant) and then mixed together for each cultivar. 
$0.2 \%$ for 'Bai Lu' (Fig. 3B), and 20.7\% \pm $1.1 \%$ for 'Hong Ying' (Fig. 3C).

Microspore development. Two water lily cultivars, Fen Zhuang with high pollen viability and Bai $\mathrm{Lu}$ with low pollen viability, were used to compare the microspore development. In 'Fen Zhuang', the epidermis became flattened as the anther expanded, and the tapetal cells remained small at the microsporocyte stage (Fig. 4A). At meiotic prophase I, the tapetal cells enlarged rapidly, became vacuolated, and multinucleate after their nucleus division (Fig. 4B). At the vacuolated uninucleate pollen stage, the tapetum began to lose the wall and intrude into the locular space with the cytoplasm fusing from the periplasmodium around the microspore in the late uninucleate pollen grain stage (Fig. 4C). After this, the connective tissue degenerated and the anther dehisced from the stomium region (Fig. 4D). However, in 'Bai Lu', at meiotic prophase I, the tapetum periplasmodium flowed into the locular space surrounding the pollen grain (Fig. 4E) and the tapetum was abnormally enlarged (Fig. $4 \mathrm{~F})$. At the vacuolated uninucleate pollen stage, only fragments of the tapetum remain, and the anther layer cells appear shrunken and the pollen grains deformed (Fig. 4G). Subsequently, the cell boundary, which was

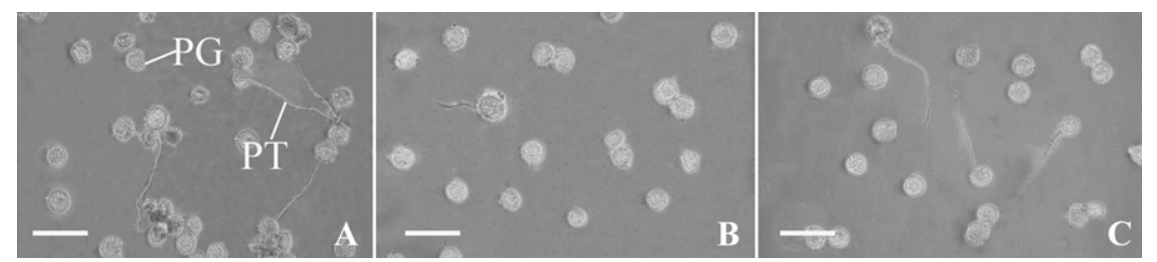

Fig. 3. Pollen viability of three male parents in culture medium. (A-C) After $6 \mathrm{~h}$ of culturing in culture medium, germination behaviors of pollen grains of 'Fen Zhuang', 'Bai Lu', and 'Hong Ying', respectively. $\mathrm{PT}=$ pollen tube; $\mathrm{PG}=$ pollen grain; scale bar $=50 \mu \mathrm{m}$.
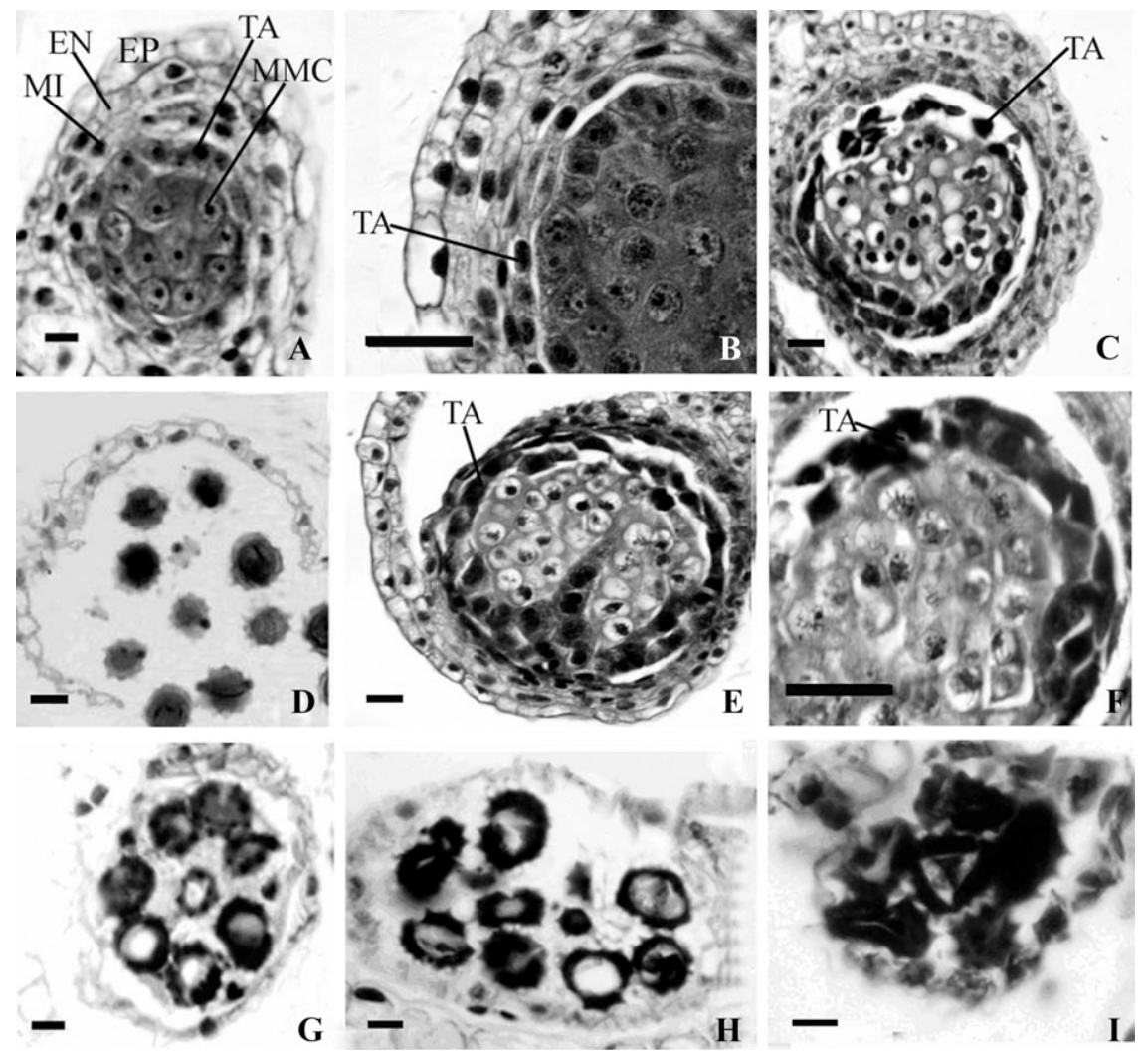

I.

Fig. 4. Microspore development in 'Fen Zhuang' and 'Bai Lu'. (A) Anther cell types present and the pattern of anthers defined at the microsporocyte stage in 'Fen Zhuang'. (B) The tapetum becomes large and vacuolated at meiotic prophase I in 'Fen Zhuang'. (C) The disintegrating tapetum at the vacuolated uninucleate pollen stage in 'Fen Zhuang'. (D) A dehiscent anther in 'Fen Zhuang'. (E) The tapetum periplasmodium flowed into the locular space surrounding the pollen grain at meiotic prophase I in 'Bai Lu'. (F) An abnormally enlarged tapetum at meiotic prophase I in 'Bai Lu'. (G) At the vacuolated uninucleate pollen stage, only fragments of the tapetum remain, the anther layer cells appear shrunken, and pollen grains deformed in 'Bai Lu'. (H) The anther layers have shrunk and microgametogenesis has been arrested in 'Bai Lu'. (I) Remnants of pollen grains and a shrunken anther in 'Bai $\mathrm{Lu}$ '. EN = endothecium; $\mathrm{EP}=$ epidermis; $\mathrm{MI}=$ middle layer; $\mathrm{MMC}=$ microsporocyte; $\mathrm{TA}=$ tapetum; $\mathrm{bar}=$ $10 \mu \mathrm{m}$. between the anther layers, became clear and the pollen grains had an abnormal appearance (Fig. 4H). No mature trinucleated pollen grains were observed, and almost all of them appeared to be irregular in shape (Fig. 4I).

Pollen behavior on stigmas after pollination. In the reciprocal crosses of $\mathrm{FH}$ and $\mathrm{HF}$, the number of germinated pollen grains on each stigma increased at $6 \mathrm{~h}$ after pollination; the highest number was attained $12 \mathrm{~h}$ after pollination and thereafter gradually decreased. For example, the average number of pollen grains germinating on the stigma increased slowly between 2 and $6 \mathrm{~h}$ after pollination in $\mathrm{FH}$ and $\mathrm{HF}$, in which an average of 15 and 9.3 pollen grains, respectively, were found to have germinated on each stigma $6 \mathrm{~h}$ after pollination. After that, a large number of pollen grains germinated with 65.7 and 43.3 at $12 \mathrm{~h}$ after pollination, respectively. Then, $24 \mathrm{~h}$ after pollination, the number had decreased to 45.4 and 30 respectively (Table 3 ). Moreover, these pollen grains germinated normally and the pollen tubes could penetrate the stigma surface in the FH and HF crosses (Fig. 5B and F). However, the number of germinated pollen grains per stigma in FB and $\mathrm{HB}$ was drastically reduced compared with the pollinations in FH and HF (Table 3), and only a few pollen grains germinated on each stigma between 2 and $24 \mathrm{~h}$ after pollination (Fig. 5A and E). Similarly, only 2.7 and two pollen grains had germinated on each stigma $12 \mathrm{~h}$ after pollination in $\mathrm{BF}$ and $\mathrm{BH}$, respectively (Table 3 ). In the two crosses involving 'Bai Lu', the accumulation of callose between the stigma and the surface of pollen grains and the inhibition of pollen tube growth was commonly observed (Fig. 5C-D).

Embryo development, endosperm development, and seed set. The zygote divided rapidly and a globular embryo, abundant perisperm, and endosperm were observed $5 \mathrm{~d}$ after pollination in $\mathrm{FH}$ (Fig. 6A). By $15 \mathrm{~d}$ after pollination, the zygote had developed into the ellipse embryo (Fig. 6B). Then after $20 \mathrm{~d}$ of rapid cell divisions, the zygote had formed a diamond embryo and the majority of the endosperm had degenerated (Fig. 6C). The percentage of normal embryos at three different time points after pollination in six water lily crosses is presented in Table 4 . Normal globular embryos were observed in only $3.1 \%$ and $4.2 \%$ of the ovaries in $\mathrm{FB}$ and $\mathrm{HB}$, respectively. It should be noted that in $\mathrm{BF}$ and $\mathrm{BH}$ after pollination, no normal embryos were observed (Table 4). In addition, embryo degeneration occurred in the reciprocal crosses of 'Fen Zhuang' and 'Hong Ying' (FH and HF). The percentage of normal embryos gradually decreased for $\mathrm{FH}$ and $\mathrm{HF}$ (Fig. 6D-F) with the values of $43.6 \%$ and $37.2 \%$ at $5 \mathrm{~d}, 31.4 \%$ and $26.4 \%$ at $15 \mathrm{~d}$, and $19.7 \%$ and $14.7 \%$ at $20 \mathrm{~d}$ after pollination, respectively (Table 4).

Seed set varied greatly among the six water lily crosses (Table 4). For example, no seeds were obtained in $\mathrm{FB}, \mathrm{BF}, \mathrm{BH}$, and $\mathrm{HB}$; however, seed set was $10.9 \%$ for $\mathrm{FH}$ and $7.3 \%$ for $\mathrm{HF}$. 
Table 3. Number of germinated pollen grains on the stigma after pollination in six water lily crosses. ${ }^{2}$

\begin{tabular}{lrrrrrr}
\hline Time after & \multicolumn{6}{c}{ Number of germinated pollen grains per stigma } \\
\cline { 2 - 7 } pollination (h) & \multicolumn{1}{c}{ FB } & \multicolumn{1}{c}{ FH } & \multicolumn{1}{c}{ BF } & \multicolumn{1}{c}{ BH } & \multicolumn{1}{c}{ NB } & \multicolumn{1}{c}{ HF } \\
\hline 2 & $0 \mathrm{a}$ & $2 \pm 0.6 \mathrm{~d}$ & $0.3 \pm 0.3 \mathrm{a}$ & $0.7 \pm 0.3 \mathrm{a}$ & $0 \mathrm{a}$ & $2.3 \pm 0.9 \mathrm{~d}$ \\
6 & $0.3 \pm 0.3 \mathrm{a}$ & $15 \pm 2.1 \mathrm{c}$ & $2.3 \pm 1.2 \mathrm{a}$ & $1.7 \pm 0.8 \mathrm{a}$ & $1 \pm 0.6 \mathrm{a}$ & $9.3 \pm 1.2 \mathrm{c}$ \\
12 & $2 \pm 1.2 \mathrm{a}$ & $65.7 \pm 4.1 \mathrm{a}$ & $2.7 \pm 0.8 \mathrm{a}$ & $2 \pm 1.2 \mathrm{a}$ & $1.3 \pm 0.3 \mathrm{a}$ & $43.3 \pm 4.1 \mathrm{a}$ \\
24 & $1 \pm 0.6 \mathrm{a}$ & $45.4 \pm 4.4 \mathrm{~b}$ & $1.7 \pm 0.9 \mathrm{a}$ & $0.7 \pm 0.7 \mathrm{a}$ & $1 \pm 0.6 \mathrm{a}$ & $30 \pm 2.5 \mathrm{~b}$ \\
\hline
\end{tabular}

${ }^{2}$ Values (mean \pm SD) followed by the same letter are not significantly different at $\alpha=0.05$ with the Bonferroni $t$ test.

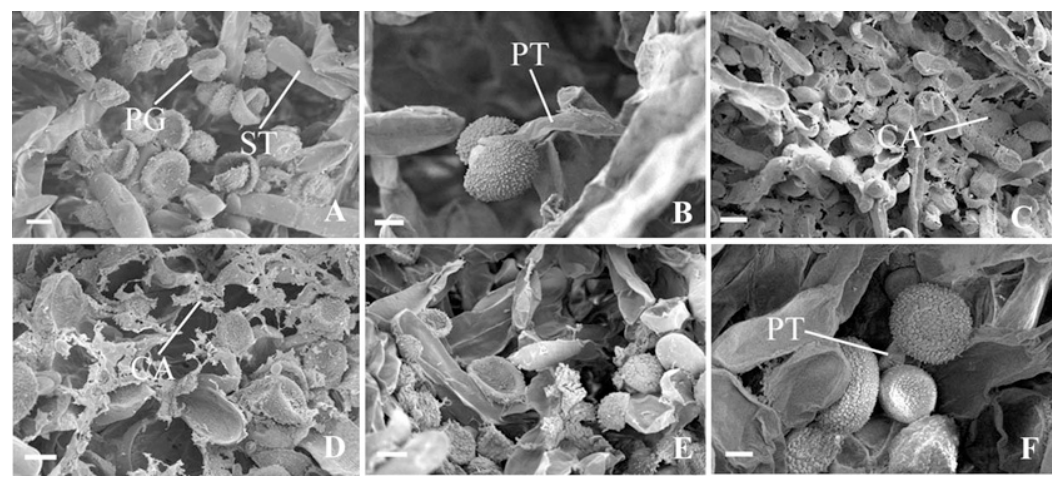

Fig. 5. Germination behaviors of pollen grains on the stigma after pollination in Nymphaea spp. (A) Abnormal pollen grains that failed to penetrate the stigma surface in FB between 2 and $24 \mathrm{~h}$ after pollination. Scale bar $=20 \mu \mathrm{m}$. (B) Many pollen grains germinated on the stigma at $12 \mathrm{~h}$ after pollination in $\mathrm{FH}$, and pollen tubes penetrated the stigma and grew through the transmitting tissues of the style. Scale bar $=10 \mu \mathrm{m}$. (C-D) Only a few pollen grains germinated on each stigma at $12 \mathrm{~h}$ after pollination in $\mathrm{BF}$ and $\mathrm{BH}$. Accumulation of callose (CA) between the stigma and the surface of the pollen grains was commonly observed. Scale bar $=10 \mu \mathrm{m}$. (E) Abnormal pollen grains failed to penetrate the stigma surface in HB between 2 and $24 \mathrm{~h}$ after pollination. Scale bar $=10 \mu \mathrm{m}$. (F) Many pollen grains germinated on the stigma at $12 \mathrm{~h}$ after pollination in HF, and pollen tubes (PT) penetrated the stigma and grew through the transmitting tissues of the style. Scale bar $=20 \mu \mathrm{m}$. ST $=$ stigma; $\mathrm{PG}=$ pollen grain; $\mathrm{CA}=$ callose.

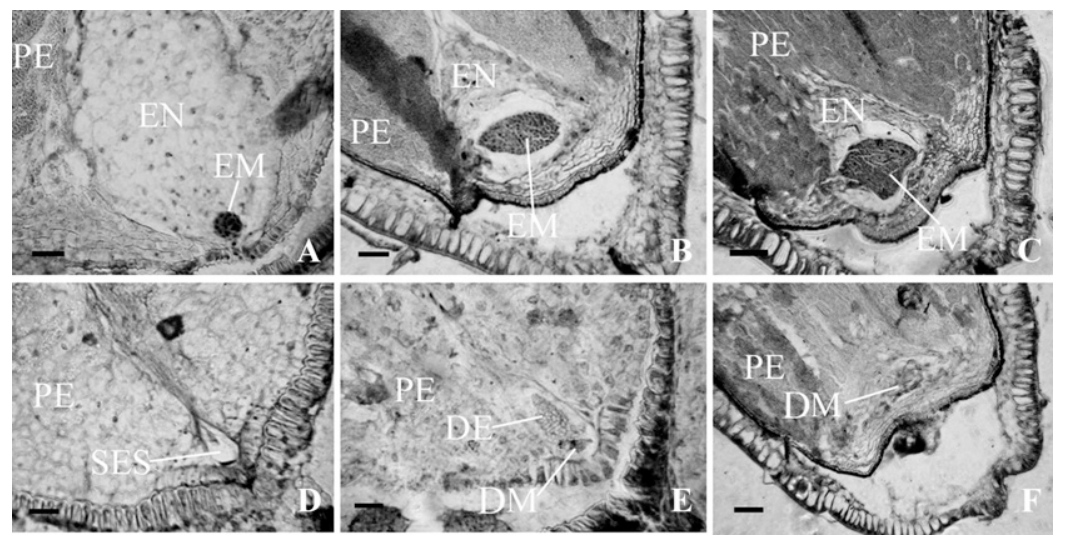

Fig. 6. Anatomical structure of the ovule of Nymphaea spp. after pollination. (A) Globular embryo, abundant perisperm, and endosperm at $5 \mathrm{~d}$ after pollination in FH. (B) Embryo at $15 \mathrm{~d}$ after pollination in FH. (C) Embryo, abundant perisperm, and little endosperm at $20 \mathrm{~d}$ after pollination in FH. (D) Failure of fertilization in FH. (E) At $15 \mathrm{~d}$ after pollination, nearly all the cells in the embryo and endosperm have degenerated, and perisperm was degenerating in FH. (F)At $20 \mathrm{~d}$ after pollination, most cells in the embryo and endosperm have degenerated, and perisperm was degenerating in $\mathrm{FH}$. EN = endosperm; $\mathrm{EM}=$ embryo $; \mathrm{PE}=$ perisperm; $\mathrm{SES}=$ shrunken embryo sac; $\mathrm{DE}=$ degradative endosperm; $\mathrm{DM}=$ degradative perisperm; scale $\mathrm{bar}=20 \mu \mathrm{m}$.

\section{Discussion}

Pollen viability is considered to be an important factor that influences seed or fruit production (Dafni and Firmage, 2000). There is a risk of reduced seed production or even pollination failure if low-quality pollen grains are transported to the stigma (Aleemullah viability of 'Bai Lu' was responsible for the failure of the crosses FB and HB. Only a few pollen grains germinated on each stigma between 2 and $24 \mathrm{~h}$ after pollination (Figs. $5 \mathrm{~A}$ and $\mathrm{E}$ ), and the percentages of normal embryos at $5 \mathrm{~d}$ after artificial pollination were $3.1 \%$ and $4.2 \%$ for $\mathrm{FB}$ and $\mathrm{HB}$, respectively (Table 4). In general, the formation of viable pollen depends on coordination in the growth of reproductive and non-reproductive tissues, especially with respect to the interaction of the tapetum and the microspores (Engelke et al., 2002). The tapetum feeds the developing microspores and then degenerates (Papini et al., 1999). Aberrant tapetal behavior has been associated with male sterility in many species (Meric et al., 2003; Shi et al., 2010). In the cultivar Fen Zhuang, the tapetum began to degenerate at the uninucleate pollen grain stage, whereas in 'Bai Lu', this process was already evident by meiotic prophase I. The tapetum periplasmodium flowed into the locular space surrounding the pollen grain and the tapetum was abnormally enlarged. Such processes probably induced premature degeneration of the tapetum, which resulted in the nutritional stress on the microspores of 'Bai $\mathrm{Lu}$ ' and the development of abnormal pollen grains. The SEM observations revealed the percentage of pollen with normal morphology for 'Bai $\mathrm{Lu}$ ' was only $8.9 \%$ and that most of pollen was abnormal with shrunken and irregular shapes. The high levels of abnormal pollen inevitably led to low pollen viability (Ćalić et al., 2013; Liu et al., 2003; Pipino et al., 2011). These results showed that the main factor responsible for the reduction of pollen viability in 'Bai Lu' was the aberrant tapetal development. In addition, although the pollen viability of 'Hong Ying' was higher than $20 \%$, the percentages of normal embryos observed $5 \mathrm{~d}$ after artificial pollination were 43.6 and $0 \%$ for $\mathrm{FH}$ and $\mathrm{BH}$, respectively (Table 4). Therefore, the fertilization rate of ovules not only had a close relationship with pollen viability, but also was more closely related to the absolute quantity of pollen grains germinating on stigmas (Sun et al., 2011). These results may suggest that factors other than pollen viability were responsible for the differences in the number of normal embryos present $5 \mathrm{~d}$ after artificial pollination.

After pollination, the journey of the pollen tube through the gynoecium is a complex process, which involves many interactions, including cell-cell recognition and cellular signaling (De Graaf et al., 2001; FranklinTong, 1999). Failures in pollination are thought to be widespread in plants and a common cause of low seed set (Hodnett et al., 2005; Lee et al., 2008; Marta et al., 2004; Pellegrino et al., 2005; Ram et al., 2006; Spielman and Scott 2008). More recently, in studies of the factors affecting seed set in several chrysanthemum and water lotus crosses, it was found that a low number of germinated pollen grains and the abnormal growth of most of the pollen tubes were the main causes of the failure of these crosses 
Table 4. Percentage of normal embryo at three dates after pollination and seed set after artificial pollination in six water lily crosses. ${ }^{\mathrm{z}}$

\begin{tabular}{lccc}
\hline Crosses & Days after pollination & $\begin{array}{c}\text { Percentage of } \\
\text { normal embryo (\%) }\end{array}$ & $\begin{array}{c}\text { Seed set after artificial } \\
\text { pollination (\%) }\end{array}$ \\
\hline FB & 5 & $3.1 \pm 1.2 \mathrm{a}$ & $0 \mathrm{c}$ \\
& 15 & $0 \mathrm{~b}$ & \\
FH & 20 & $0 \mathrm{~b}$ & $10.9 \pm 1.0 \mathrm{a}$ \\
& 5 & $43.6 \pm 4.1 \mathrm{a}$ & \\
$\mathrm{BF}$ & 15 & $31.4 \pm 3.2 \mathrm{~b}$ & $0 \mathrm{c}$ \\
& 20 & $19.7 \pm 2.4 \mathrm{c}$ & \\
& 5 & 0 & $\mathrm{c}$ \\
$\mathrm{BH}$ & 15 & 0 & \\
& 20 & 0 & $0 \mathrm{c}$ \\
$\mathrm{HB}$ & 5 & 0 & \\
& 15 & 0 & $7.3 \pm 0.8 \mathrm{~b}$ \\
$\mathrm{HF}$ & 20 & 0 & \\
& 5 & $4.2 \pm 1.4 \mathrm{a}$ & $0 \mathrm{~b}$ \\
& 15 & $0 \mathrm{~b}$ & \\
\hline
\end{tabular}

${ }^{\mathrm{z}}$ Values (mean $\pm \mathrm{SD}$ ) followed by the same letter are not significantly different at $\alpha=0.05$ with the Bonferroni $t$ test.

(Sun et al., 2010; Teng et al., 2012). The present results showed significant differences in the number of germinated pollen grains on the stigma $12 \mathrm{~h}$ after pollination among the six crosses. In addition, the number of germinated pollen grains on the stigma in each cross was positively correlated with the percentage of normal globular embryos at $5 \mathrm{~d}$ after pollination and seed set (Tables 3 and 4). Moreover, in the BF and BH crosses, large amounts of callose were deposited in some pollen grains, which resulted in a failure of the pollen tubes to penetrate the stigma (Fig. 5 ). Therefore, the low viability for $\mathrm{BF}$ and $\mathrm{BH}$ crosses may be the result of low pollen grain germination and abnormal growth of their pollen tubes. Knox et al. (1972) suggested that at pollination, proteins essential for germination and pollen tube growth as well as "recognition substances" related to compatibility reactions were released from the pollen wall. Such self-recognition systems operate in a number of incompatible reactions in plant hybridizations (Sun et al., 2010; Teng et al., 2012), and it is possible that a similar system may be responsible for the low rate of pollen germination in the $\mathrm{BF}$ and $\mathrm{BH}$ crosses. In the $\mathrm{FH}$ and $\mathrm{HF}$ crosses, however, the interaction was compatible and resulted in the normal germination of many pollen grains on stigmas and the normal growth of pollen tubes. Because pollen-pistil interactions are complex, further investigation into the causes of pollen germination inhibition and pollen tube growth are necessary to increase stigmatic receptivity in water lily crosses.

Embryo development is another factor influencing seed set, and embryo abortion usually leads to low seed set (Datson et al., 2006; Deng et al., 2012; Mallikarjuna and Saxena, 2002; Ndoutoumou et al., 2007). For instance, Sun et al. (2010) reported that embryo abortion was a critical factor resulting in the failure of the interspecies cross between $D$. grandiflorum 'Yuhuaxingchen' and $D$. nankingense as well as a main factor leading to the low seed set of 'Yuhuaxingchen' and D. zawadskii. Deng et al. (2010b) found that a post-fertilization barrier led to the abortion of many embryos at various developmental stages before maturation, which significantly reduced the fecundity between Chrysanthemum and Ajania. This phenomenon was also observed in the reciprocal crosses of 'Fen Zhuang' and 'Hong Ying'. In the $\mathrm{FH}$ and $\mathrm{HF}$ there were $43.6 \%$ and $37.2 \%$ normal embryos present $5 \mathrm{~d}$ after pollination, respectively. However, the corresponding values for $20 \mathrm{~d}$ after pollination decreased to $19.7 \%$ and $14.7 \%$ (Table 4 ). These results showed that another factor related to the reduction in the seed set of both water lily crosses was embryo abortion. The majority of the aborted embryos appeared to have degraded endosperms and it was thought that the abortion was a result of endosperm failure causing nutrient deficiency ( $\mathrm{Hu}, 2005)$. Therefore, it is suggested that for the embryo to continue to develop, it needs nutrients to grow. When the embryo reaches the late globular stage $15 \mathrm{~d}$ after pollination, nearly all the cells in the endosperm had degenerated and perisperm was degenerating in FH (Fig. 6F), which prevents the change to the next stage of development and results in embryo death. The same abortion mechanisms can occur in any embryonic development.

In conclusion, our systematic investigation showed that the possible factors influencing fecundity of six water lily crosses included pollen morphology, pollen viability, microspore development, pistil receptivity, and embryo and endosperm development. The main factors related to the failure of FB and $\mathrm{HB}$ crosses were low pollen viability and embryo abortion. Low pistil receptivity was responsible for the failure of the crosses $\mathrm{BF}$ and $\mathrm{BH}$, whereas the low fecundity of $\mathrm{FH}$ and HF was mainly attributable to embryo abortion. However, the mechanisms involved in low stigma receptivity and embryo abortion remain unknown, and further studies are required to better understand these factors in water lily cultivars.

\section{Literature Cited}

Aleemullah, M., A.M. Haigh, and P. Holford. 2000. Anthesis, anther dehiscence, pistil receptivity and fruit development in the Longum group of Capsicum annuum. Austral. J. Expt. Agr. 40:755-762.

Ćalić, D., N. Devrnja, I. Kostić, and M. Kostić. 2013. Pollen morphology, viability, and germination of Prunus domestica cv. Požegača. Sci. Hort. 115:118-122.

Dafni, A. and D. Firmage. 2000. Pollen viability and longevity: Practical ecological and evolutionary implications. Plant Syst. Evol. 222:113-132.

Datson, P.M., B.G. Murray, and K.R.W. Hammett. 2006. Pollination systems, hybridization barriers and meiotic chromosome behaviour in Nemesia hybrids. Euphytica 151:173-185.

De Graaf, B.H.J., J.W.M. Derksen, and C. Mariani. 2001. Pollen and pistil in the progamic phase. Sex. Plant Reprod. 14:41-55.

Deng, Y.M., S.M. Chen, N.J. Teng, F.D. Chen, F.T. Li, A.P. Song, and Z.Y. Guan. 2010a. Flower morphologic anatomy and embryological characteristics in Chrysanthemum multicaule (Asteraceae). Sci. Hort. 124:500-505.

Deng, Y.M., J.F. Jiang, S.M. Chen, N.J. Teng, A.P. Song, Z.Y. Guan, W.M. Fang, and F.D. Chen. 2012. Combination of multiple resistance traits from wild relative species in chrysanthemum via trigeneric hybridization. PLoS One 7:1-15.

Deng, Y.M., N.J. Teng, S.M. Chen, F.D. Chen, Z.Y. Guan, A.P. Song, and Q.S. Chang. 2010b. Reproductive barriers in the intergeneric hybridization between Chrysanthemum grandiflorum (Ramat.) Kitam. and Ajania przewalskii Poljak. (Asteraceae). Euphytica 174:41-50.

Engelke, T., S. Hulsmann, and T. Tatlioglu. 2002. A comparative study of microsporogenesis and anther wall development in different types of genic and cytoplasmic male sterilities in chives. Plant Breed. 121:254-258.

Franklin-Tong, V.E. 1999. Signaling and the modulation of pollen tube growth. Plant Cell 11:727738.

Hodnett, G.L., B.L. Burson, W.L. Rooney, S.L. Dillon, and H.J. Price. 2005. Pollen-pistil interactions result in reproductive isolation between Sorghum bicolor and divergent Sorghum species. Crop Sci. 45:1403-1409.

Hu, S.Y. 2005. Reproductive biology of angiosperms. Higher Education Press, Beijing, China.

Huang, G.Z., H.Q. Deng, Z. Li, and G. Li. 2009. Water lily. China Forestry Press, Beijing, China.

Huang, Z.H., J.M. Zhu, X.J. Mu, and J.X. Lin. 2004. Pollen dispersion, pollen viability and pistil receptivity in Leymus chinensis. Ann. Bot. (Lond.) 93:295-301.

Jin, B., L. Wang, J. Wang, N.J. Teng, X.D. He, X.J. $\mathrm{Mu}$, and Y.L. Wang. 2010. The structure and roles of sterile flowers in Viburnum macrocephalum f. keteleeri (Adoxaceae). Plant Biol. 12:853-862.

Knox, R.B., R.R. Willing, and A.E. Ashford. 1972. Role of pollen wall proteins as recognition substances in interspecific hybridization in poplars. Nature 237:381-383.

Koshy, K.C. and G. Jee. 2001. Studies on the absence of seed set in Bambusa vulgaris. Curr. Sci. 82:375-378.

Lee, C.B., L.E. Page, B.A. McClure, and T.P. Holtsford. 2008. Postpollination hybridization barriers in Nicotiana section Alatae. Sex. Plant Reprod. 21:183-195. 
Liu, W.G., M. Wang, and Z.H. Yan. 2003. Observation and comparison on pollen morphology of different ploidy watermelon. Acta Horticulturae Sinica 30:328-330.

Mallikarjuna, N. and K.B. Saxena. 2002. Production of hybrids between Cajanus acutifolius and C. cajan. Euphytica 124:107-110.

Marta, A.E., E.L. Camadro, J.C. Díaz-Ricci, and A.P. Castagnaro. 2004. Breeding barriers between the cultivated strawberry, Fragaria $\times$ ananass $a$, and related wild germplasm. Euphytica 136:139-150.

Meric, C., F. Dane, and G. Olgun. 2003. Histological aspects of anther wall in male fertile and cytoplasmic male sterile Helianthus annuus L. (sunflower). Asian J. Plant Sci. 3:145-150.

Ndoutoumou, P.N., A. Toussaint, and J.P. Baudoin. 2007. Embryo abortion and histological features in the interspecific cross between Phaseolus vulgaris L. and P. coccineus L. Plant Cell Tissue Organ Cult. 88:329-332.

Papini, A., S. Mosti, and L. Brighigna. 1999. Programmed-cell-death events during tapetum development of angiosperms. Protoplasma 207:213221.
Pellegrino, G., F. Bellusci, and A. Musacchio. 2005. Evidence of post-pollination barriers among three colour morphs of the deceptive orchid Dactylorhiza sambucina (L.) Soó. Sex. Plant Reprod. 18:179-185.

Pipino, L., M.C. Van Labeke, A. Mansuino, V. Scariot, A. Giovannini, and L. Leus. 2011. Pollen morphology as fertility predictor in hybrid tea roses. Euphytica 178:203-214.

Ram, S.G., K. Sundaravelpandian, M. Kumar, K.K. Vinod, J.R.K. Bapu, and T.S. Raveendran. 2006. Pollen-pistil interaction in the interspecific crosses of Sesamum sp. Euphytica 152:379-385.

Shi, S., D. Ding, S. Mei, and J. Wang. 2010. A comparative light and electron microscopic analysis of microspore and tapetum development in fertile and cytoplasmic male sterile radish. Protoplasma 241:37-49.

Spielman, M. and R.J. Scott. 2008. Polyspermy barriers in plants: From preventing to promoting fertilization. Sex. Plant Reprod. 21:53-65.

Sun, C.Q., F.D. Chen, N.J. Teng, Z.L. Liu, W.M. Fang, and X.L. Hou. 2010. Factors affecting seed set in the crosses between Dendranthema grandiflorum (Ramat.) Kitamura and its wild species. Euphytica 171:181-192.

Sun, C.Q., Z.Z. Huang, Y.L. Wang, F.D. Chen, N.J. Teng, W.M. Fang, and Z.L. Liu. 2011 Overcoming pre-fertilization barriers in the wide cross of chrysanthemum by using special pollination techniques. Euphytica 178:195-202.

Tang, F.P., F.D. Chen, S.M. Chen, N.J. Teng, and W.M. Fang. 2009. Intergeneric hybridization and relationship of genera within the tribe Anthemideae Cass. [I. Dendranthema crassum (Kitam.) Kitam. $\times$ Crossostephium chinense (L.) Makino]. Euphytica 169:133-140.

Teng, N.J., Y.L. Wang, C.Q. Sun, W.M. Fang, and F.D. Chen. 2012. Factors influencing fecundity in experimental crosses of water lotus (Nelumbo nucifera Gaertn.) cultivars. BMC Plant Biol. 12:82.

Wilcock, C. and R. Neiland. 2002. Pollination failure in plants: Why it happens and when it matters. Trends Plant Sci. 17:270-277.

Zhang, H.P., W.M. Fang, F.D. Chen, Y.S. Ding, N.X. Cui, and J.J. Gu. 2009. Investigation on the morphological diversity of taxa in genus Nymphaea. J. Nanjing Agr. Univ. 32:47-52. 